\title{
Salinomycin may inhibit the cancer stem-like populations with increased chemoradioresistance that nasopharyngeal cancer tumorspheres contain
}

\author{
GONG ZHANG, SHUPING ZHANG, JINJIN REN, CHUNXIAO YAO, \\ ZHONGREN ZHAO, XIURONG QI, XIAOFENG ZHANG, SHUYE WANG and LEI LI \\ Department of Radiotherapy, People's Hospital of Shanxi Province, Taiyuan, Shanxi 030012, P.R. China
}

Received January 1, 2016; Accepted November 7, 2017

DOI: $10.3892 / \mathrm{ol} .2018 .8923$

\begin{abstract}
Tumor recurrence and metastasis of nasopharyngeal cancer (NPC) often result in the failure of treatment due to chemoradioresistance. Cancer stem cells (CSCs) have been observed to drive tumor initiation and tumor chemoradioresistance. Therefore, the poor prognosis of advanced NPC is likely to result from the failure to kill CSCs. Sphere formation may be used as an experimental method to enrich potential CSC subpopulations. At present, there are few reports on NPC tumorspheres. The present study focused on examining the cancer stem-like properties of NPC tumorspheres from NPC cell lines. Western blot analysis revealed that NPC tumorspheres had a higher expression of stem cell markers Nanog homeobox and SRY-box 2, compared with parental cells. It was additionally verified that NPC tumorspheres contained a high aldehyde dehydrogenase (ALDH) enzymatic activity compared with parental cells. ALDH+ cells were amplified by 9- to 10-fold in tumorspheres, compared with parental cells $(1.8$ vs. $16.9 \%)$. The tumorsphere cells exhibited an increased half maximal inhibitory concentration value of $>10$-fold with cisplatin compared with the control parental cells. Compared with the parental cells, the percentage of side population cells in the tumorsphere cell population increased significantly (10.3 vs. $2.3 \%$; $\mathrm{P}<0.05$ ). NPC tumorsphere cells demonstrated enhanced resistance to radiation. Further investigation verified that salinomycin inhibited NPC CSCs by selectively targeting its stem cells. Altogether, the data revealed that NPC tumorspheres contain cancer stem-like populations with increased chemoradioresistance. It was suggested that the serum-free culture of NPC cells may provide an appropriate model for researching the sensitivity of CSCs to therapeutic agents. It
\end{abstract}

Correspondence to: Dr Gong Zhang, Department of Radiotherapy, People's Hospital of Shanxi Province, 29 Shuangta Street, Taiyuan, Shanxi 030012, P.R. China

E-mail: zhanggong7446@163.com

Key words: nasopharyngeal cancer, cancer stem cell, tumorsphere, chemoradioresistance, salinomycin was additionally revealed that salinomycin is an efficient inhibitor of NPC CSCs, supporting the hypothesis that salinomycin may eliminate CSCs and imply a need for further clinical evaluation.

\section{Introduction}

Nasopharyngeal cancer (NPC) is a rare cancer globally, but is prevalent in Southeast Asia (1). Due to its radiosensitivity, radiotherapy is the primary treatment of NPC. In locally advanced stages, combined radiotherapy and chemotherapy have been considered to be an effective treatment in order to improve survival, preferred to radiotherapy alone (2). Local control rate of NPC has improved markedly in the past decade (3). However, local recurrence and metastasis remain the primary causes of mortality from this cancer, particularly in advanced stages (4), and management of local treatment failure remains a challenge in NPC treatment.

Emerging evidence supports the notion that cancer stem cells (CSCs) contribute to NPCs resistance to chemoradiation, which results in a poor prognosis for numerous different types of human cancer (5). CSCs possess the ability to recreate the complete phenotypic heterogeneity of the parental tumor cells. These cells possess distinct surface markers allowing for self-renewal (6). Multiple stem cell markers, including nanog homeobox (Nanog), SRY-box 2 (Sox-2) and aldehyde dehydrogenase (ALDH) have been used successfully to identify CSCs in normal and tumor tissue $(7,8)$. Furthermore, side population (SP) cells exhibit CSC characteristics in NPC (9).

The anchorage-independent serum-free culture of stem cells was instrumental in the research of CSCs $(10,11)$. Sphere formation may be specifically used to enrich the potential CSC subpopulation as a functional method $(12,13)$. Therefore, the suspension culture system may maintain CSCs in their undifferentiated condition, facilitating their enrichment. However, few reports exist at present regarding tumorspheres in NPC. Therefore, the present study evaluated NPC cell subsets with CSC properties.

Enhanced chemoradioresistance to therapy is another characteristic of CSCs and has been identified in numerous different types of cancer cells $(14,15)$. The NPC tumorsphere may be a valuable model for the further research of CSCs and 
chemoradioresistance. In the present study, it was therefore evaluated as to whether NPC tumorsphere cells acquired the chemoradiation-resistant characteristics of CSCs.

Although NPC CSCs may be experimentally identified, drugs or compounds that selectively target NPC CSCs have not yet emerged. Salinomycin is a carboxylic polyether ionophore extracted from Streptomyces albus (16). Salinomycin has been identified as a selective inhibitor of breast and lung CSCs $(17,18)$, however its function in the inhibition of NPC $\mathrm{CSC}$ remains to be revealed. In the present study, a tumorsphere was successfully used to enrich NPC CSCs, and the results demonstrated that salinomycin was able to kill NPC CSCs.

\section{Materials and methods}

Cells and culture conditions. SUNE-1 and 5-8F human nasopharyngeal cancer cell lines were purchased from the Type Culture Collection of the Chinese Academy of Sciences (Shanghai, China). SUNE-1 and 5-8F cells were cultured in DMEM medium (Hyclone; GE Healthcare Life Sciences, Logan, UT, USA) supplemented with $10 \%$ fetal bovine serum (FBS; Hyclone; GE Healthcare Life Sciences) and $100 \mathrm{U} / \mathrm{ml}$ penicillin/streptomycin (Gibco; Thermo Fisher Scientific, Inc., Waltham, MA, USA). Cells were cultured in a humidified air with $5 \% \mathrm{CO}_{2}$ at $37^{\circ} \mathrm{C}$.

Tumorsphere culture and selection. SUNE-1 and 5-8F cells $(1,000$ cells $/ \mathrm{ml})$ were cultivated in serum-free Ham's F-12 medium (Gibco; Thermo Fisher Scientific, Inc.), supplemented with B27 (1:50; Gibco; Thermo Fisher Scientific, Inc.), $20 \mathrm{ng} / \mathrm{ml}$ epidermal growth factor (Invitrogen; Thermo Fisher Scientific, Inc.) and $20 \mathrm{ng} / \mathrm{ml}$ fibroblast growth factor (Invitrogen; Thermo Fisher Scientific, Inc.) at $37^{\circ} \mathrm{C}$. To expand spheres in vitro, spheres were harvested by centrifugation at $125 \mathrm{x} \mathrm{g}$ for $5 \mathrm{~min}$ at $24^{\circ} \mathrm{C}$, separated to single cells and then cultured for $72 \mathrm{~h}$ at $37^{\circ} \mathrm{C}$ to produce tumorspheres of the next generation. The tumorspheres were filtered using a cell strainer (BD Biosciences, San Jose, CA, USA). Spheroids with a diameter $>40 \mu \mathrm{m}$ were selected to perform the experiment.

Western blot analysis. The tumorspheres and parental cells were washed three times with $5 \mathrm{ml}$ phosphate-buffered saline. Total protein was extracted from cells using a cell lysis buffer $(20 \mathrm{mmol} / \mathrm{l}$ Tris- $\mathrm{HCl}, 150 \mathrm{mmol} / \mathrm{l} \mathrm{NaCl}$, $1 \%$ NP40, 5 mmol/1 EDTA, 1 mmol/1 Na3VO4; pH 7.5) supplemented with a protease inhibitor cocktail and a phosphatase inhibitor (Sigma-Aldrich; Merck KGaA, Darmstadt, Germany), and was incubated on ice for $30 \mathrm{~min}$. Protein concentration was determined using a bicinchoninic acid protein assay kit (Pierce; Thermo Fisher Scientific, Inc.). Protein $(50 \mu \mathrm{g} /$ lane $)$ were loaded and separated on a $10 \%$ gel using SDS-PAGE and then transferred to polyvinylidene membranes. Following blocking in $50 \mathrm{~g} / 1$ non-fat milk in tris-buffered saline with Tween $20(20 \mathrm{mmol} / 1 \mathrm{Tris}-\mathrm{HCl}$, $137 \mathrm{mmol} / \mathrm{l} \mathrm{NaCl}$ and $1 \mathrm{~g} / \mathrm{l}$ Tween 20; $\mathrm{pH}$ 7.6) for $2 \mathrm{~h}$ at room temperature, the membranes were incubated at $4^{\circ} \mathrm{C}$ overnight with the following primary antibodies: Mouse anti-Nanog (dilution, 1:1,000; cat. no. sc-374001; Santa Cruz Biotechnology, Inc., Dallas, TX, USA), Sox-2 (dilution,
1:1,000; cat. no. sc-365823, Santa Cruz Biotechnology) and GAPDH (dilution, 1:1,000; cat. no. sc-51907; Santa Cruz Biotechnology). The membranes were then incubated for $1 \mathrm{~h}$ at $24^{\circ} \mathrm{C}$ with horseradish peroxidase-conjugated anti-mouse immunoglobulin secondary antibodies (dilution, 1:1,000; cat. no. A32729, Invitrogen; Thermo Fisher Scientific, Inc.). Finally, the membranes were visualized using the Image lab 3.0.1 software (Bio-Rad Laboratories, Inc., Hercules, CA, USA) following analysis using an enhanced chemiluminescence-Plus detection system (Bio-Rad Laboratories, Inc.).

ALDEFLUOR assay by fluorescence-activated cell sorting (FACS). The identification of ALDH activity using the ALDEFLUOR assay (Stem Cell Technologies, Inc., Vancouver, BC, Canada) was followed by FACS analysis. Cells were suspended in ALDEFLUOR assay buffer, which contains ALDH substrate, and were incubated for $40 \mathrm{~min}$ at $37^{\circ} \mathrm{C}$. As a negative control, for each sample of cells an aliquot was treated with $50 \mathrm{mM}$ diethylaminobenzaldehyde (DEAB), a specific ALDH inhibitor. FACS analysis was performed using a FACSAria flow cytometer (BD Biosciences). The results were analyzed using FlowJo 7.6.3 software (FlowJo LLC, Ashland, OR, USA).

Hoechst staining and SP cell assay. The parental or spheroid cells were suspended in DMEM/2\% FBS at a density of $1 \times 10^{6}$ cells $/ \mathrm{ml}$. The cells were then dispersed into single cells and incubated with Hoechst 33342 dye $(5 \mu \mathrm{g} / \mathrm{ml}$; Sigma-Aldrich; Merck KGaA) either alone or in combination with verapamil $(50 \mathrm{mmol} / \mathrm{ml}$; Sigma-Aldrich; Merck $\mathrm{KGaA}$ ) for $90 \mathrm{~min}$ at $37^{\circ} \mathrm{C}$. Following incubation, cells were washed with PBS and stained with propidium iodide $(1 \mu \mathrm{g} / \mathrm{ml}$; Sigma-Aldrich; Merck KGaA) for $30 \mathrm{~min}$ at $4^{\circ} \mathrm{C}$. Finally, the cells were maintained at $4^{\circ} \mathrm{C}$ for the flow cytometric analysis and for the sorting of the SP fraction using a FACSAria flow cytometer. The results were analyzed using the FlowJo 7.6.3 software.

Drug sensitivity assay. Parental or spheroid cells were collected in 96-well microplates at a density of 3,000 cells per well. The cells were then treated with increasing concentrations of cisplatin $\left(10^{-7}, 10^{-6}, 10^{-5}\right.$ and $10^{-4} \mathrm{M}$; Sigma-Aldrich, St. Louis, MO, USA). Subsequent to incubation for $72 \mathrm{~h}$ at $37^{\circ} \mathrm{C}$, an MTT assay was used to evaluate the cell viability. The number of living cells was calculated according to the absorbance at $490 \mathrm{~nm}$. Each experiment was repeated three times.

Clone formation assay. Parental or spheroid cells were irradiated at indicated doses (0, 2, 4, 6, 8 and 10 Gy). Irradiation of cells was performed using $250 \mathrm{kV}$ orthovoltage X-rays by a linear accelerator (Elekta Instrument AB, Stockholm, Sweden). Following irradiation, the cells were collected and subsequently replated in a $30-\mathrm{mm}$ culture dish at a density of 200-5,000 cells per dish. Subsequent to culturing for 14 days at $37^{\circ} \mathrm{C}$, cells were fixed with $10 \%$ formalin and stained with $0.1 \%$ crystal violet for $15 \mathrm{~min}$ at $24^{\circ} \mathrm{C}$; clones consisting of $>50$ cells were selected. The survival fraction was calculated by dividing the number of colonies formed by the number of cells plated. The data were entered into single hit multi-target formula, as follows: $S=1-\left(1-e^{-D / D^{\circ}}\right)^{N}$ (where $D$, quasi-threshold 
dose; $\mathrm{D}^{0}$, mean lethal dose; $\mathrm{N}$, extrapolation number; and $\mathrm{S}$, survival fraction). Graphpad Prism 5.0 (Graphpad Software, Inc., La Jolla, CA, USA) was used to draw the survival fraction curve. Experiments were repeated three times.

Sphere formation efficiency assay. Parental or spheroid cells were collected in 96-well microplates at a density of 3,000 cells per well. The cells were pretreated with dimethyl sulfoxide (DMSO; Sigma-Aldrich; Merck KGaA), $2 \mu \mathrm{M}$ cisplatin (Sigma-Aldrich; Merck KGaA) and $2 \mu \mathrm{M}$ salinomycin (Sigma-Aldrich; Merck KGaA) for $72 \mathrm{~h}$ at $37^{\circ} \mathrm{C}$. Subsequently, the cells were transferred into serum-free Ham's F-12 medium in 24-well microplates at a density of 100 cells/well. After $48 \mathrm{~h}$, the tumorspheres were counted under a light microscope (magnification, x200; Nikon Corporation, Tokyo, Japan). Each experiments was repeated for three times.

Statistical analyses. $\mathrm{P}<0.05$ was considered to indicate a statistically significant difference. Data were analyzed using the SPSS 19.0 statistical software package (IBM Corp., Armonk, NY, USA) and were presented as the mean \pm the standard deviation. Differences between the groups were determined using a one-way analysis of variance and least significant difference method for multiple comparisons.

\section{Results}

NPC tumorspheres contain cells with cancer stem-like properties. It has been reported that breast CSC populations may be generated in vitro as mammospheres under serum-free culture conditions (19). In the present study, the NPC CSC population was enriched from the SUNE-1 cell line. Parental cells were cultivated in serum-free culture. After culturing for $72 \mathrm{~h}$, floating tumorspheres were formed (Fig. 1A). SUNE-1 spheroids with a diameter of $>40 \mu \mathrm{m}$, which were filtered out using a cell strainer, were selected. Two typical CSC markers, Nanog and Sox2, were detected using immunoblotting. As revealed in Fig. 1B, a marked increase in the expression of Nanog and Sox 2 were observed in the SUNE-1 spheroids, compared with the parental cells. ALDH has been identified as a potential marker for NPC CSCs (20). ALDH is a detoxifying enzyme responsible for the oxidation of intracellular aldehydes. To further confirm this finding, an ALDEFLUOR assay was used to assess ALDH enzymatic activity in the SUNE-1 spheroids. ALDEFLUOR-positive cells were increased 9-10-fold in tumorsphere cells, compared with the parental cells (1.8 vs. 16.9\%; Fig. 1C). The results indicated that NPC tumorspheres possessed increased stem-like cancer cells.

NPC tumorspheres exhibit increased chemoresistance. Tumor cells resistant to chemotherapy occur partly due to the overexpression of the ATP-binding cassette sub-family (21). This characteristic is associated with the ability to expel dyes, identified by flow cytometry to be a SP (22). SP cells have been reported to possess NPC CSC properties (23). In the present study, NPC tumorsphere cells cultured in serum-free cultures were detected to possess a 4.5 -fold increase in the proportion of SP cells compared with the parental cells (10.3 vs. $2.3 \%$; Fig. 2A). Furthermore, the sensitivity of NPC tumorsphere cells and parental cells to cisplatin, which is usually used for
A

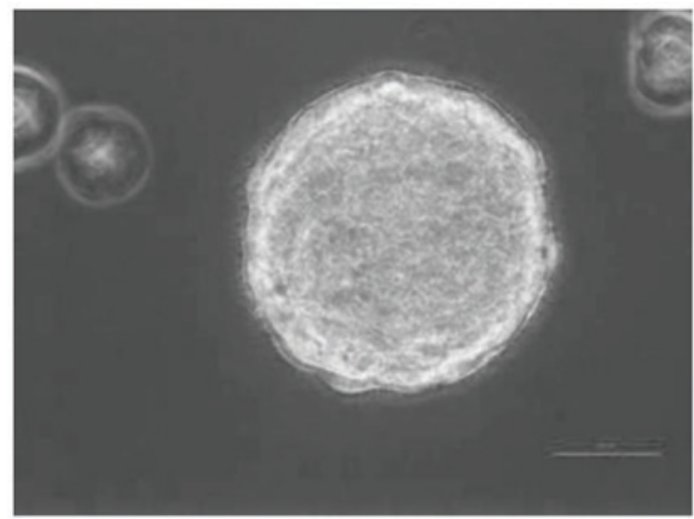

B

Parental

Spheroid

Nanog

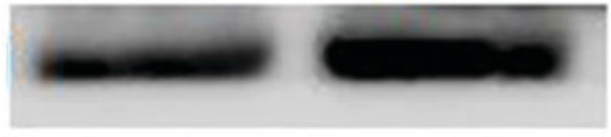

Sox2

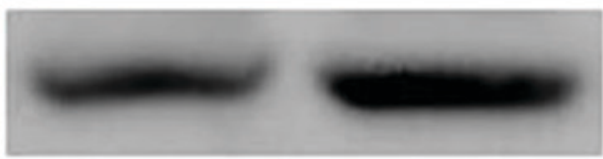

GAPDH

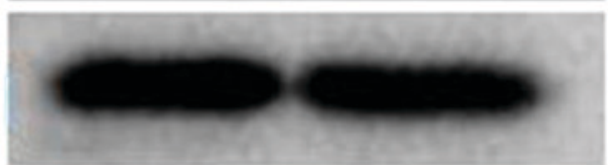

C
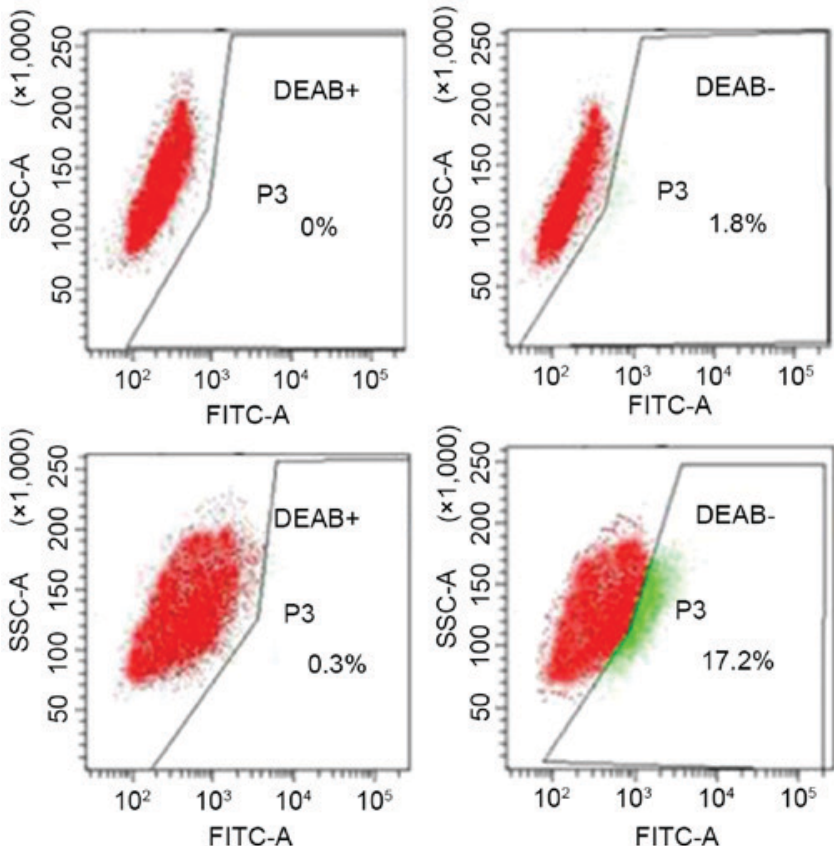

Figure 1. NPC tumorsphere formation and detection of CSC markers. (A) A light microscopic-derived image of SUNE-1 NPC spheroid cultivated in serum-free culture for $72 \mathrm{~h}$. Scale bars, $100 \mu \mathrm{m}$ (magnification, $\mathrm{x} 200$ ). (B) Western blot analysis of Nanog and Sox-2 expression between the parental and spheroid SUNE-1 cells. (C) ALDEFLUOR assay of Aldehyde dehydrogenase-positive cells of parental (upper, 1.8\%) and spheroid (lower 16.9\%) SUNE-1 cells. NPC, nasopharyngeal cancer; CSC, cancer stem cell; Nanog, nanog homeobox; Sox-2, SRY-box 2.

chemotherapy against NPC, was examined. The tumorsphere cells from the spheroids demonstrated an increased half maximal inhibitory concentration value of $>10$-fold with cisplatin compared with the control parental cells (Fig. 2B). These 

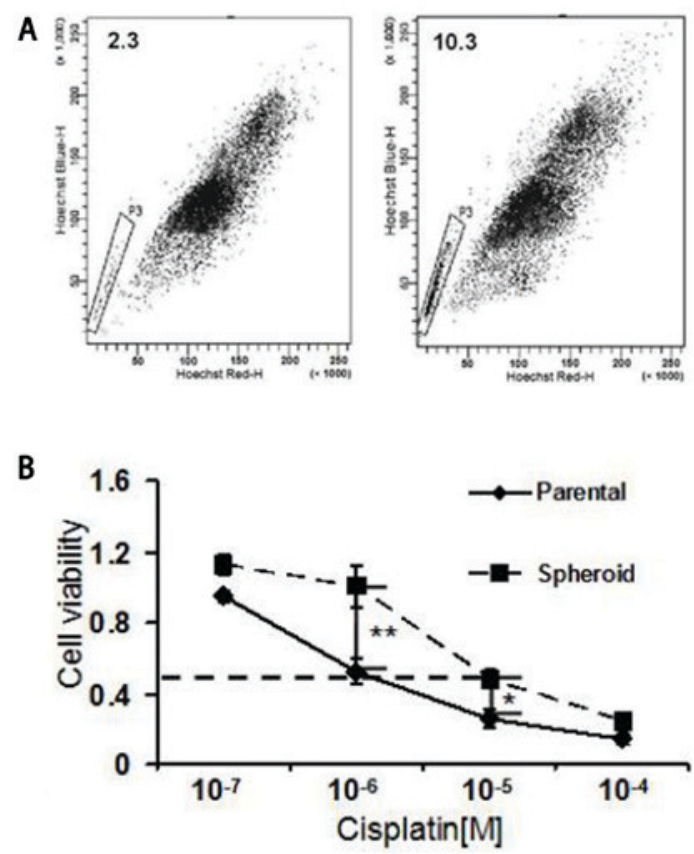

Figure 2. Proportion of SP cells and resistance to cisplatin between nasopharyngeal cancer tumorsphere cells and parental cells. (A) FACS analysis of the proportion of SP cells in parental (left panel, 2.3\%) and spheroid (right panel, 10.3\%) SUNE-1 cell groups. (B) Dose-response curves of parental and spheroid SUNE-1 cells following $72 \mathrm{~h}$ of treatment with cisplatin. Transverse line corresponds to the half maximal inhibitory concentration value. Bars represent the mean \pm standard deviation. ${ }^{*} \mathrm{P}<0.05\left(10^{-5} \mathrm{M}\right.$ cisplatin in parental cells vs. spheroid cells) ${ }^{* *} \mathrm{P}<0.01\left(10^{-6} \mathrm{M}\right.$ cisplatin in parental cells vs. spheroid cells). SP, side population; FACS, fluorescence-activated cell sorting.

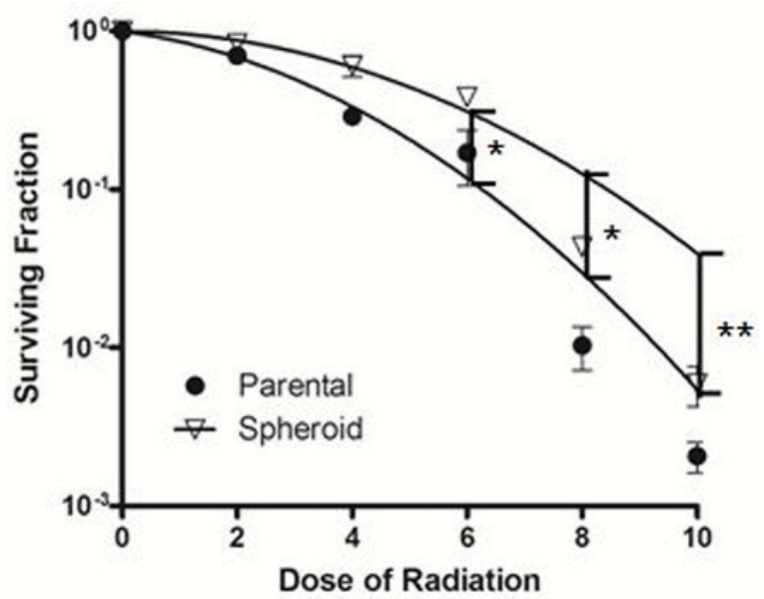

Figure 3. Survival curves of parental and spheroid SUNE-1 cells that underwent radiotherapeutic treatment. Bars represent the mean \pm standard deviation. ${ }^{*} \mathrm{P}<0.05$ (6 and 8 Gy radiation in parental cells vs. spheroid cells), ${ }^{* *} \mathrm{P}<0.01$ (10 Gy radiation in parental cells vs. spheroid cells).

results indicate that NPC tumorspheres possess increased chemoresistant properties of CSCs.

NPC tumorsphere cells demonstrate enhanced resistance to radiation. Radiotherapy is the primary treatment of NPC due to its radiosensitivity (24). To assess whether self-renewing cells from spheroids possessed a radiotherapy resistant phenotype, the radiosensitivity of parental and tumorsphere cells was analyzed using a clone formation assay. Following
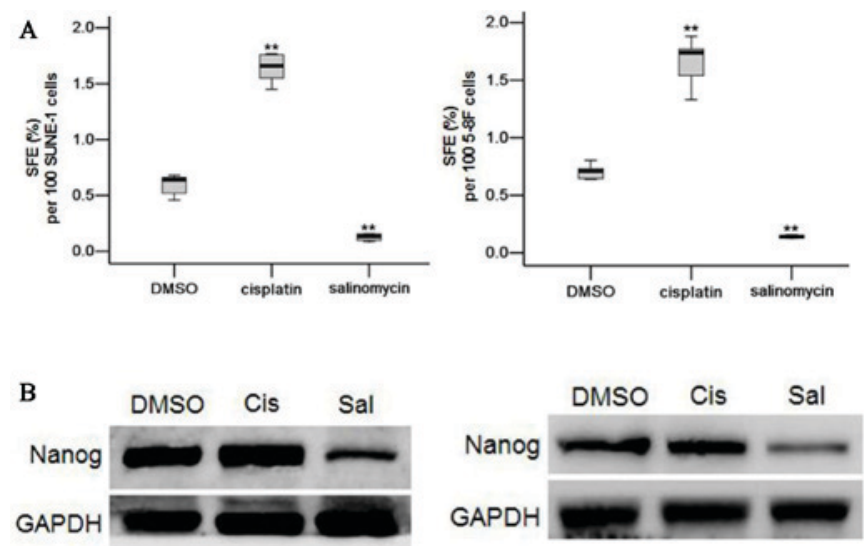

Figure 4. Effect of salinomycin on the SFE and Nanog expression of SUNE-1 and 5-8F cells. (A) SFE of SUNE-1 (left panel) and 5-8F (right panel) cells in serum-free medium, which were pre-treated with DMSO, cisplatin and salinomycin for $72 \mathrm{~h}$ in serum-contained medium. Results were presented as box plots. ${ }^{* *} \mathrm{P}<0.01$ vs. DMSO. (B) Immunoblotting of Nanog in SUNE-1 (left panel) and 5-8F (right panel) spheroid cells treated with DMSO, cisplatin and salinomycin for $72 \mathrm{~h}$. SFE, sphere formation efficiency; Nanog, nanog homeobox; DMSO, dimethyl sulfoxide.

radiotherapeutic treatment, the survival fraction (SF) of the cells cultured as spheroids was significantly decreased compared with that of the parental cells [spheroid cells, mean SF at 6 Gy $(\mathrm{SF} 6 \mathrm{~Gy})=0.383 \pm 0.064$ vs. parental cells SF6 $\mathrm{Gy}=0.171 \pm 0.113 ; \mathrm{P}<0.05$; Fig. 3]. These results supported radioresistance characteristics of NPC CSC-like cells.

Salinomycin selectively kills NPC CSCs. Salinomycin has been reported to possess potent anti-CSC activity (25). As a functional measure of CSC frequency, the ability of SUNE-1 and 5-8F cells to form tumorspheres following treatment for $72 \mathrm{~h}$ with salinomycin, cisplatin or a DMSO control when cultured in suspension cultures, was tested as an in vitro measure of CSC activity. Parental SUNE-1 and 5-8F cells were treated by DMSO, cisplatin $(2 \mu \mathrm{M})$ or salinomycin $(2 \mu \mathrm{M})$ for $72 \mathrm{~h}$. Following treatment, tumor cells were cultivated in suspension cultures. Sphere formation efficiency (SFE) of SUNE-1 and 5-8F cells with the salinomycin treatment demonstrated a significant 4.7-fold and 5.0-fold decrease relative to DMSO treatment (0.592 spheres vs. 0.126 spheres per 100 SUNE-1 cells, $\mathrm{P}<0.01 ; 0.706$ spheres vs. 0.142 spheres per 100 5-8F cells, $\mathrm{P}<0.05$; Fig. 4A). In contrast, cisplatin treatment demonstrated a significant increase in the SFE of SUNE-1 and 5-8F cells compared with DMSO treatment ( $\mathrm{P}<0.01$; Fig. 4A). Nanog, a CSC marker, of SUNE-1 and $5-8 \mathrm{~F}$ tumorsphere cells treated for $72 \mathrm{~h}$ with DMSO, cisplatin $(2 \mu \mathrm{M})$ and salinomycin $(2 \mu \mathrm{M})$ was also directly assayed. SUNE-1 and 5-8F tumorsphere cells treated with salinomycin presented a decrease in Nanog expression, compared with the DMSO control. The expression of Nanog did not decrease in the cisplatin-treated SUNE-1 and 5-8F cells (Fig. 4B). These results suggested that salinomycin may inhibit NPC CSC properties.

\section{Discussion}

Radiotherapy is the initial treatment mode of NPC and using radiotherapy in combination with chemotherapy is recommended for the treatment of locally advanced tumors (26). 
Tumor recurrence and metastasis often result in the failure of treatment due to chemoradioresistance (27).

A previous study reported the application of serum-free culture to enrich and isolate potential CSC subpopulations in multiple different types of tumor (28). In general, as with all stem cells, the tumorsphere forming cells are capable of proliferation, self-renewal and exhibit increased tumorigenicity (29). In the present study, a comprehensive investigation of tumorsphere cells that are derived from the SUNE-1 cell line was provided. It was revealed that SUNE-1 tumorsphere cells acquire the characteristics of CSCs, with the increased expression of stem cell markers (Nanog and Sox-2), compared with the parental cells. It has been demonstrated that in SUNE-1 spheroids, a comparatively large subpopulation of cells had elevated the enzymatic activity of ALDH. These results suggest that NPC tumorsphere cells are associated with cancer stem-like populations.

Enhanced chemoresistance to therapy is another characteristic of CSCs that has been identified in numerous different types of cancer cells (30). In the present study, the tumorsphere cells demonstrated increased resistance, compared with that in the parental cells, to cisplatin treatment. NPC tumorspheres also exhibited an increased prevalence of SP cells. Therefore, it was suggested that the non-adherent tumorspheres cultured in serum-free conditions possessed NPC CSC properties. Suspension culture may be used to enrich drug-resistant NPC cells.

Radioresistance has been implied to be associated with CSCs in multiple types of cancer $(31,32)$. Radiotherapy is the most important method in the treatment of NPC. NPC cells are more sensitive to radiation than other cancer cells (33). In the present study, tumorsphere cells displayed enhanced resistance to radiation compared with that displayed by its radiosensitive SUNE-1 parental cells. Therefore, eradicating radiotherapy-resistant cells is critical for successful anti-NPC therapy.

Salinomycin is a polyether anticoccidial drug produced by an S. albus strain. Previously, salinomycin had been reported to possess potent anti-CSC activity (34). The present study revealed that a decrease of SFE was observed following salinomycin treatment in vitro, implying that salinomycin may kill NPC CSCs selectively. NPC CSCs are more sensitive to salinomycin compared with the parental cells. In contrast, an increase in SFE was observed following cisplatin treatment in vitro; it was theorized that the increased SFE was due to the already increased proportion of CSCs present in the NPC cells treated with cisplatin. This may be due to the fact that cisplatin may only kill common tumor cells rather than CSCs (35).

To conclude, the present study demonstrated that chemoresistant NPC tumorsphere cells are rich in 'stem-cell-like' tumor cells and may be inhibited by salinomycin selectively. An effective method for the enrichment of CSCs was provided, which is beneficial for the research of the characteristics of NPC stem-like cells in terms of their biology and their unique cell surface markers. Finding novel therapies to overcome chemoresistance in NPC CSCs is key to improving long-term survival rates for patients with NPC.

\section{Acknowledgements}

Not applicable.

\section{Funding}

The present study was supported by the National Natural Science Foundation of China (grant no. 81402458) and the Basic Research Project of Shanxi Province (grant no. 2014021037-4).

\section{Availability of data and materials}

All data generated or analyzed during this study are included in this published article.

\section{Authors' contributions}

GZ performed the FACS analysis, and SZ performed the irradiation. JR performed the tumorsphere culture and selection. CY and ZZ conducted the western blot analysis. XQ and $\mathrm{XZ}$ conducted the clone formation assay. SW was responsible for the drug sensitivity assay. GZ and LL performed the statistical analysis. GZ designed the study and wrote the manuscript.

\section{Ethics approval and consent to participate}

Not applicable.

\section{Consent for publication}

Not applicable.

\section{Competing interests}

The authors declare that they have no competing interests.

\section{References}

1. Lee AW, Ma BB, Ng WT and Chan AT: Management of nasopharyngeal carcinoma: Current practice and future perspective. J Clin Oncol 33: 3356-3364, 2015.

2. Tan WL, Tan EH, Lim DW, Ng QS, Tan DS, Jain A and Ang MK: Advances in systemic treatment for nasopharyngeal carcinoma. Chin Clin Oncol 5: 21, 2016.

3. Sze H, Blanchard P, Ng WT, Pignon JP and Lee AW: Chemotherapy for nasopharyngeal carcinoma-current recommendation and controversies. Hematol Oncol Clin North Am 29: 1107-1122, 2015.

4. Li JG, Venigalla P, Leeman JE, LaPlant Q, Setton J, Sherman E, Tsai J, McBride S, Riaz N and Lee N: Patterns of nodal failure after intensity modulated radiotherapy for nasopharyngeal carcinoma. Laryngoscope 127: 377-382, 2017.

5. Greve B, Kelsch R, Spaniol K, Eich HT and Götte M: Flow cytometry in cancer stem cell analysis and separation. Cytometry A 81: 284-293, 2012.

6. Dalerba P, Cho RW and Clarke MF: Cancer stem cells: Models and concepts. Annu Rev Med 58: 267-284, 2007.

7. Mathieu J, Zhang Z, Zhou W, Wang AJ, Heddleston JM, Pinna CM, Hubaud A, Stadler B, Choi M, Bar M, et al: HIF induces human embryonic stem cell markers in cancer cells. Cancer Res 71: 4640-4652, 2011.

8. Wu A, Luo W, Zhang Q, Yang Z, Zhang G, Li S and Yao K: Aldehyde dehydrogenase 1, a functional marker for identifying cancer stem cells in human nasopharyngeal carcinoma. Cancer Lett 330: 181-189, 2013.

9. Guo D, Xu BL, Zhang XH and Dong MM: Cancer stem-like side population cells in the human nasopharyngeal carcinoma cell line cne-2 possess epithelial mesenchymal transition properties in association with metastasis. Oncol Rep 28: 241-247, 2012. 
10. Bez A, Corsini E, Curti D, Biggiogera M, Colombo A, Nicosia RF, Pagano SF and Parati EA: Neurosphere and neurosphere-forming cells: Morphological and ultrastructural characterization. Brain Res 993: 18-29, 2003

11. Shi X, Gipp J and Bushman W: Anchorage-independent culture maintains prostate stem cells. Dev Biol 312: 396-406, 2007.

12. Lee CH, Yu CC, Wang BY and Chang WW: Tumorsphere as an effective in vitro platform for screening anti-cancer stem cell drugs. Oncotarget 7: 1215-1226, 2016.

13. Dontu G, Abdallah WM, Foley JM, Jackson KW, Clarke MF Kawamura MJ and Wicha MS: In vitro propagation and transcriptional profiling of human mammary stem/progenitor cells. Genes Dev 17: 1253-1270, 2003.

14. Lan X, Wu YZ, Wang Y, Wu FR, Zang CB, Tang C, Cao S and Li SL: CD133 silencing inhibits stemness properties and enhances chemoradiosensitivity in CD133-positive liver cancer stem cells. Int J Mol Med 31: 315-324, 2013.

15. Yang CF, Peng LX, Huang TJ, Yang GD, Chu QQ, Liang YY, Cao X, Xie P, Zheng LS, Huang HB, et al: Cancer stem-like cell characteristics induced by EB virus-encoded LMP1 contribute to radioresistance in nasopharyngeal carcinoma by suppressing the p53-mediated apoptosis pathway. Cancer Lett 344: 260-271, 2014.

16. Zhou S, Wang F, Wong ET, Fonkem E, Hsieh TC, Wu JM and Wu E: Salinomycin: A novel anti-cancer agent with known anti-coccidial activities. Curr Med Chem 20: 4095-4101, 2013.

17. Fu YZ, Yan YY, He M, Xiao QH, Yao WF, Zhao L, Wu HZ, Yu ZJ, Zhou MY, Lv MT, et al: Salinomycin induces selective cytotoxicity to MCF-7 mammosphere cells through targeting the Hedgehog signaling pathway. Oncol Rep 35: 912-922, 2016.

18. Wang Y: Effects of salinomycin on cancer stem cell in human lung adenocarcinoma A549 cells. Med Chem 7: 106-111, 2011.

19. Ponti D, Costa A, Zaffaroni N, Pratesi G, Petrangolini G, Coradini D, Pilotti S, Pierotti MA and Daidone M: Isolation and in vitro propagation of tumorigenic breast cancer cells with stem/progenitor cell properties. Cancer Res 65: 5506-5511, 2005

20. Yu F, Sim AC, Li C, Li Y, Zhao X, Wang DY and Loh KS Identification of a subpopulation of nasopharyngeal carcinoma cells with cancer stem-like cell properties by high aldehyde dehydrogenase activity. Laryngoscope 123: 1903-1911, 2013.

21. McIntosh K, Balch C and Tiwari AK: Tackling multidrug resistance mediated by efflux transporters in tumor-initiating cells. Expert Opin Drug Metab Toxicol 12: 633-644, 2016.

22. Boesch M, Zeimet AG, Fiegl H, Wolf B, Huber J, Klocker H, Gastl G, Sopper S and Wolf D: High prevalence of side population in human cancer cell lines. Oncoscience 3: 85-87, 2016.

23. Yu S, Zhang R, Liu F, Wang H, Wu J and Wang Y: Notch inhibition suppresses nasopharyngeal carcinoma by depleting cancer stem-like side population cells. Oncol Rep 28: 561-566, 2012.
24. Pan JJ, Ng WT, Zong JF, Lee SW, Choi HC, Chan LL, Lin SJ, Guo QJ, Sze HC, Chen YB, et al: Prognostic nomogram for refining the prognostication of the proposed 8th edition of the AJCC/UICC staging system for nasopharyngeal cancer in the era of intensity-modulated radiotherapy. Cancer 122: 3307-3315, 2016.

25. Zhang C, Tian Y, Song F, Fu C, Han B and Wang Y: Salinomycin inhibits the growth of colorectal carcinoma by targeting tumor stem cells. Oncol Rep 34: 2469-2476, 2015.

26. Zhang B, Hu Y, Xiong RH, Pan YF, Xu QL, Kong XY, Cai R, Chen QQ, Tang HY and Jiang W: Matched analysis of induction chemotherapy plus chemoradiotherapy versus induction chemotherapy plus radiotherapy alone in locoregionally advanced nasopharyngeal carcinoma: A multicenter study. Oncotarget 8: 14078-14088, 2017.

27. $\mathrm{Xu} \mathrm{C}$, Chen YP and Ma J: Clinical trials in nasopharyngeal carcinoma-past, present and future. Chin Clin Oncol 5: 20, 2016

28. Hirschhaeuser F, Menne H, Dittfeld C, West J, Mueller-Klieser W and Kunz-Schughart LA: Multicellular tumor spheroids: An underestimated tool is catching up again. J Biotechnol 148: 3-15, 2010.

29. Gou S, Liu T, Wang C, Yin T, Li K, Yang M and Zhou J: Establishment of clonal colony-forming assay for propagation of pancreatic cancer cells with stem cell properties. Pancreas 34: 429-435, 2007.

30. Liu W, Gao Q, Chen K, Xue X, Li M, Chen Q, Zhu G and Gao Y: Hiwi facilitates chemoresistance as a cancer stem cell marker in cervical cancer. Oncol Rep 32: 1853-1860, 2014.

31. Pranatharthi A, Ross C and Srivastava S: Cancer stem cells and radioresistance: Rho/ROCK pathway plea attention. Stem Cells Int 2016: 5785786, 2016.

32. De Bacco F, D'Ambrosio A, Casanova E, Orzan F, Neggia R, Albano R, Verginelli F, Cominelli M, Poliani PL, Luraghi P, et al: MET inhibition overcomes radiation resistance of glioblastoma stem-like cells. EMBO Mol Med 8: 550-568, 2016.

33. Lee AW, Ng WT, Chan YH, Sze H, Chan C and Lam TH: The battle against nasopharyngeal cancer. Radiother Oncol 104: 272-278, 2012.

34. Gupta PB, Onder TT, Jiang G, Tao K, Kuperwasser C, Weinberg RA and Lander ES: Identification of selective inhibitors of cancer stem cells by high-throughput screening. Cell 138: 645-659, 2009.

35. Yang J, Zhang K, Wu J, Shi J, Xue J, Li J, Chen J, Zhu Y, Wei J, He $J$ and Liu X: Wnt5a increases properties of lung cancer stem cells and resistance to cisplatin through activation of Wnt5a/PKC signaling pathway. Stem Cells Int 2016: 1690896, 2016. 